\title{
Evasão escolar no Ensino Superior: uma revisão literária entre os anos de 2014 a
}

\section{0}

\author{
School dropout in Higher Education: a literature review in the years 2014 to 2020
}

Abandono escolar en la Educación Superior: una revisión de la literatura en los años 2014 a 2020

Henrique Rosario Carvalho Esteves

ORCID: https://orcid.org/0000-0002-5927-0131 Universidade Federal dos Vales de Jequitinhonha e Mucuri, Brasil

E-mail: henriqueestevesccb@hotmail.com

Carlos Alberto Dias

ORCID: https://orcid.org/0000-0002-5286-6637 Universidade Federal dos Vales de Jequitinhonha e Mucuri, Brasil

E-mail: carlos.dias@ufvjm.edu.br

Ciro Meneses Santos

ORCID: https://orcid.org/0000-0001-8687-0987 Universidade Federal dos Vales de Jequitinhonha e Mucuri, Brasil E-mail: cirosantos@gmail.com

Agnaldo Keiti Higuch

ORCID: https://orcid.org/0000-0001-8719-6154 Universidade Federal dos Vales de Jequitinhonha e Mucuri, Brasil E-mail: Agnaldo.higuchi@ufvjm.edu.br

\begin{abstract}
Resumo
O tema evasão escolar, tem sido objeto de estudo e debate de muitos pesquisadores nos últimos anos, pois este se caracteriza como um fenômeno escolar complexo, que representa prejuízos tanto para as instituições de ensino quanto para a sociedade. O presente artigo se trata de uma revisão de literatura que estuda os principais temas abordados nas publicações desta temática em periódicos nacionais, analisando o panorama teórico do construto do abandono escolar elaborado entre os anos de 2014 e 2020, procurando identificar os fatores que levaram a evasão escolar no Brasil neste período. Os resultados demonstram que as evasões se deram por multifatores, mas pôde-se perceber destaques nas questões internas no que tange às metodologias e modelos de gestão das instituições de ensino. Outros fatores preponderantes de questões externas às instituições são os problemas pessoais dos estudantes e a dificuldade destes em conciliar a carga horária de trabalho com os estudos.
\end{abstract}

Palavras-chave: Evasão escolar; Abandono escolar; Educação; Instituições de ensino.

\begin{abstract}
The issue of school dropout has been the object of study and debate by many researchers in recent years, as it is characterized as a complex school phenomenon, which represents losses for both educational institutions and society. This article is a literature review, which studies the main themes addressed in publications on this topic in national journals, analyzing the theoretical panorama of the school dropout construct, developed between the years 2014 and 2020, seeking to identify the factors that led to school dropout in Brazil during this period. The results demonstrate that the evasions were due to multifactors, but it was possible to perceive highlights in the internal issues regarding the methodologies and management models of educational institutions. Other overriding factors in matters external to the institutions are the personal problems of students and their difficulty in reconciling their workload with their studies.
\end{abstract}

Keywords: School evasion; School dropout; Education; Teaching institutions.

\section{Resumen}

El tema del abandono escolar ha sido objeto de estudio y debate por parte de numerosos investigadores en los últimos años, ya que se caracteriza por ser un fenómeno escolar complejo, que representa pérdidas tanto para las instituciones educativas como para la sociedad. Este artículo es una revisión de la literatura que estudia los principales temas abordados en las publicaciones de esta temática en revistas nacionales, analizando el panorama teórico del constructo de deserción escolar elaborado entre los años 2014 y 2020, buscando identificar los factores que llevaron a la deserción escolar en Brasil durante este período. Los resultados demuestran que las evasiones se debieron a multifactores, pero fue posible percibir destaques en las cuestiones internas en cuanto a las metodologías y modelos 
de gestión de las instituciones educativas. Otros factores preponderantes de temas externos a las instituciones son los problemas personales de los estudiantes y su dificultad para conciliar su carga de trabajo con sus estudios.

Palabras clave: Deserción escolar; Evasión escolar; Educación; Instituciones de enseñanza.

\section{Introdução}

A evasão escolar está associada ao desligamento dos discentes da instituição de ensino, independentemente do motivo, exceto em casos de conclusão ou diplomação do curso. Este fenômeno reflete em múltiplas perdas para a instituição, seja pelos investimentos de recursos com os discentes, ou como também para o desenvolvimento no que tange a sociedade e cultura do país (Fritsch et al., 2015).

Essa problemática também pode ser entendida como a interrupção dos estudos e deve ser analisada como um problema educacional complexo, no qual compromete a efetivação do direito à educação no Brasil (Brasil, 2015). A evasão tem se tornado cada vez mais agravante, possuindo uma difícil compreensão e se demonstrado complexa para a sua redução.

O abandono escolar é um problema que afeta todas as instituições de ensino, sendo assim, o estudo dos fatores que levam os estudantes a abandonarem as escolas se torna fundamental, pois é necessário o entendimento destes para que se possa criar ações que almejam a diminuição da taxa de evasão.

Baggi e Lopes (2011, p.371) afirmam que há a existência de múltiplos fatores que levam ao abandono escolar nas instituições de ensino, podendo estar relacionadas aos contextos sociais, culturais, políticos e econômicos. Eles afirmam a necessidade de se realizar uma reflexão sistemática sobre as metodologias de avaliações das instituições com a evasão.

A realização deste trabalho de revisão se torna relevante no meio acadêmico ao possibilitar aos escritores a identificação prévia das pesquisas que já foram realizadas e desenvolvidas na área, como também servir de base para futuros estudos da mesma temática.

O tema em questão possui grande importância para a efetivação da educação no país, como também para o desenvolvimento dele, tornando-se necessária uma maior reflexão e entendimento para criação de medidas preventivas e na redução das taxas de evasões escolares. A pesquisa vem como forma de contribuição ao agregar conhecimento para os demais pesquisadores da área, para as instituições de ensino, governo e educadores.

Por fim, o presente artigo surge com intuito de realizar um maior debate sobre o tema e identificar suas principais temáticas. Sendo assim, coloca-se a seguinte pergunta de pesquisa: quais são os fatores que levaram a evasão escolar no ensino superior nos anos de 2016 a 2020 no Brasil? A partir desse contexto, este estudo realizará uma revisão bibliográfica dos temas abordados de publicações entre os anos de 2014 a 2020 sobre a evasão escolar no ensino superior.

\section{Metodologia}

A pesquisa é de caráter documental exploratório e natureza quantitativa com utilização de técnicas de coleta de dados. Denzin e Lincoln (2006) a investigação bibliográfica envolve uma abordagem interpretativa fundamentando-se na buscas e análises de materiais produzidos sobre um determinado tema, na qual foi abordado por outros pesquisadores previamente como em livros, artigos e demais publicações cientificas (Unesp, 2015).

Segundo o documento "Tipos de Revisão de Literatura", produzido pela UNESP - Campus Botucatu, a revisão literária se categoriza como revisão narrativa, revisão sistemática e revisão integrativa. (Unesp, 2015).

O presente trabalho realizou o método de revisão bibliográfica que tem como objetivo desenvolver o estudo a partir das publicações cientificas disponíveis em trabalhos elaborado a respeito de determinado tema (Gil, 2002). Para atingir os objetivos deste trabalho foi necessário realizar um levantamento bibliográfico estacando dados sobre a evasão escolar nas instituições de ensino no período de 2014 a 2020 com o intuito de desenvolve reflexões no campo da área da educação, se 
fundamentando em sua maior parte nos trabalhos de natureza exploratória, na qual são desenvolvidas com a finalidade de realizar debates, esclarecer ou modificar conceitos e ideias, elaborando assim hipóteses pesquisáveis e formulações de possíveis questões para estudos futuros. Esse tipo de pesquisa, segundo Pereira et al., "... parte da observação organizadas de fatos, da realização de experiência, das deduções logicas e da comprovação cientifica dos resultados obtidos" e é utilizado em trabalhos no qual o tema é caracterizado como complexo e com poucas pesquisas na área (Gil, 2008; Pereira et al., 2018).

$\mathrm{Na}$ coleta de dados disponíveis nos acervos acadêmicos lizamos os seguintes descritores [Evasão Escolar OR Abandono Escolar OR Desistência Escolar] AND [Ensino Técnico OR Curso Técnico OR Segundo Grau OR Escola Técnica] considerando os conectores [OR][AND]. O levantamento foi realizado no período de outubro de 2020 a janeiro de 2021, identificando inicialmente 123 publicações, após uma primeira avaliação nas publicações retornadas forma selecionados 23 (vinte e três) artigos considerados válidos, ou seja, tiveram o intuito de identificar os fatores que levaram ao abandono escolar no ensino superior, como também a identificação das temáticas abordadas no âmbito da evasão escolar.

\section{Resultados e Discussão}

A evasão escolar é entendida como a interrupção dos estudos e deve ser analisada como um problema educacional complexo, no qual compromete a efetivação do direito à educação no Brasil (Brasil, 2015).

Fritsch (2015) afirma sobre a complexidade do fenômeno da evasão escolar, ligado ao desligamento dos estudantes com as instituições de ensino antes que estes concluam os seus cursos. A evasão escolar está relacionada à diversas causas que necessitam ser estudadas e compreendidas em seus diversos contextos, a exemplo do socioeconômico, político, educacional e outros.

Para o site Brasil Escola (2013):

O fracasso escolar e a consequente evasão, denotam o próprio fracasso das relações sociais que se expressam na realidade desumana que vivenciamos em nosso cotidiano, no qual a distância formada pela teoria e a prática desafia nossa inteligência, como por exemplo, quando se estuda sobre as medidas de higiene para se evitar doenças em locais onde a água está contaminada e não existe o mínimo de saneamento básico, uma contradição cruel.

Entre as metas propostas pelo Plano Nacional de Educação (PNE) do período de 2014-2024, pode-se observar o intuito de elevar a taxa bruta de matrícula no ensino superior em nível de graduação para 50\% e de 33\% de taxa líquida, com o foco na população de 18 a 24 anos (Brasil, 2014).

A CONAE (2010) afirma que uma democratização da educação deve ser feita assegurando também a garantia da permanência dos discentes nos cursos ingressados, não somente a oferta de vagas nas instituições de ensino.

Muitos estudos têm sido realizados com intuito de explanar e identificar os fatores que levaram a evasão nos institutos de ensino, como o trabalho dos autores Souza et al., (2019) realizando um trabalho com abordagem qualitativa sobre a evasão nos cursos presenciais de licenciatura em física, matemática e química da Universidade Federal de Goiás (UFG). O autor Daitx; Loguercio (2016) na qual estudou a evasão e retenção escolar dos discentes do curso de licenciatura em química, do Instituto de Química da UFRGS (Universidade Federal do Rio Grande do Sul), nos anos de 2009 a 2013.

Leonarde et al., (2019), por sua vez, investigaram o abandono escolar no curso de Administração na UFVJM Campus Mucuri, nos anos 2014 a 2018, ao passo que Boghi (2018) buscou trabalhar coma metodologia de pesquisa-ação com elaboração de atividades interativas com os alunos no contexto educacional, tentando viabilizar uma participação mais ativa dos discentes com a disciplina, e assim diminuir a taxa de evasão escolar no instituto de educação em análise. 
Lamers et al., (2017) e Rodrigues (2018) buscaram analisar a evasão no ensino superior, na qual o primeiro autor abordou a perspectiva dos docentes e discentes do curso de Odontologia da Universidade Federal no Sul do Brasil, dos anos de 2010 a 2014 e o segundo autor buscou avaliar o abandono no curso de especialização em Gestão em Saúde pertencente ao PNAP, ofertado pelo Núcleo de Educação a Distância (NEAD) da Universidade Federal localizada no estado de Minas Gerais.

Os autores Rangel et al., (2019), Vitelli et al., (2016) e Lima et al., (2018) realizaram trabalhos voltados para o entendimento do conceito e uso do termo evasão escolar no ensino superior. Rangel et al., (2019) buscou problematizar o conceito da evasão para se referir à saída prematura dos discentes, enquanto Vitelli et al., (2016) aborda o conceito e uso do temo evasão escolar nas produções acadêmicas. Por fim Lima et al., (2018) buscou compreender a evasão em uma instituição de ensino comunitária da região Oeste de Santa Catarina no período de 2005 a 2014.

Branco (2020) objetivou estabelecer fatores importantes que levam ao abandono na educação superior, procurando analisar micro dados e sinopses do Censo da Educação Superior (Brasil, MEC/INEP, 2002-2016), tendo como foco o contexto do estado da Paraíba. O autor Prestes (2018) analisou a evasão ocorrida na Universidade Federal da Paraíba (UFPB), demonstrando as consequências econômicas e sociais geradas pela evasão.

Nascimento; Beggiato (2020) estudaram as motivações para a evasão na graduação em Musicoterapia na Universidade Estadual do Paraná entre 2013 e 2018. Oliveira; Moreira (2016) analisaram a evasão escolar em uma instituição privada de educação superior da Região Administrativa de Ceilândia, considerando o período de 2014/1 a 2015/2, buscando traçar o perfil socioeconômico dos evadidos e as variáveis que influenciaram diretamente e/ou indiretamente na evasão, relevando a perspectiva dos próprios estudantes.

Brum et al., (2017) buscaram analisar as razões de permanência e evasão dos alunos do curso Superior em Gestão Pública do Instituto Federal de Educação, Ciência e Tecnologia de Rondônia - Campus Porto Velho Zona Norte. Rocha et al., (2020) analisou e comparou as causas para a evasão, bem como realizou um levantamento desses motivos no curso de Licenciatura em Química do Instituto Federal do Paraná - Campus Paranavaí.

Lobo et al., (2019) buscaram apresentar a representação social da insatisfação acadêmica para estudantes em situação de evasão escolar no curso de administração presencial do Centro Universitário Projeção, considerando o período de 2017 até 2018.

Wihelm e Schlosser (2019) buscaram estudar sobre a evasão universitária no Curso de licenciatura em geografia da Universidade Estadual do Oeste do Paraná (UNIOESTE), Campus Marechal Cândido Rondon. Fávero et al., (2016) analisaram as dimensões que discriminam a evasão no ensino superior de uma IES - Instituição de Ensino Superior privada do município de Blumenau.

Barbosa et al., (2016) identificaram os fatores determinantes da evasão dos discentes do Curso de Bacharelado em Ciências Contábeis de uma IES Pública. Trata-se de uma pesquisa descritiva com abordagem qualitativa, cujos dados foram coletados por meio de questionário.

Silva et al., (2018) realizaram um levantamento de alguns dos fatores que podem levar os alunos do curso de administração de uma instituição de ensino superior privada do Estado do Amazonas a evadir.

Bizarria et al., (2017) buscaram analisar as formulações estratégicas para enfrentamento da evasão em cursos do Programa Nacional de Formação em Administração Pública (PNAP) ofertados a distância em uma instituição de ensino superior do Ceará.

Guimarães et al., (2019) interpretaram o fenômeno da evasão escolar dos alunos dos cursos de graduação na UNESP/Franca do período de 2013 a 2018. Bezerra; Moreira. (2018) analisaram a evasão em cursos de graduação por meio de métricas, apoiados por visualização de dados. Por fim, Prestes; Fialho. (2018) estudaram os movimentos da evasão na educação superior, através do caso específico da Universidade Federal da Paraíba (UFPB). 


\subsection{Evasão no Ensino Superior Público}

Dentre os motivos que levaram ao abandono escolar nas instituições públicas identificados na revisão, os autores Souza et al., (2019), Daitx; Loguercio (2016), Rocha et al. (2020), Leonarde (2019), Rodrigues (2018) e Lamers et al., (2017) identificaram problemas ligados a própria instituição de ensino, na qual se encontra questões sobre as relações discentes e docentes, coordenação, metodologia de ensino e avaliação utilizada pelos docentes, como também as próprias aulas. Estes fatores provocam um alto índice de reprovações iniciais, gerando uma desmotivação nos discentes.

Leonarde (2019) reforça a necessidade de uma abordagem diferente por parte da gestão da instituição de ensino e dos docentes, pois pôde-se observar em sua pesquisa a dificuldade de adequação com a grade curricular do curso e a forma de avaliação utilizada pelos docentes, como também a interação entre alunos e professores.

O autor Souza et al., (2019) ainda afirma que a trajetória acadêmica se dá muito pela pressão social, na qual os estudantes não escolhem os cursos por vocação, mas sim por influências externas ou razões pessoais como também profissionais. Sendo assim, a falta de identificação com o curso e a carreira profissional tem se destacado dentre as causas da evasão nas pesquisas dos autores Guimarães et al., (2019), Daitx; Loguercio (2016), Nascimento; Beggiato (2020), Rocha et al., (2020) e Barbosa et al., (2016).

Rocha et al., (2020), Wihelm; Schlosser (2019), Lamers et al., (2017) indicam a falta de tempo para dedicação aos estudos, devido a carga horária de trabalho e de atividades realizadas pelos cursos como outro fator preponderante para a desistência escolar. Nascimento; Beggiato (2020), Brum et al., (2017), Rocha et al., (2020), Rodrigues (2018) e Wihelm; Schlosser (2019) afirmam que questão ligadas a fatores externos como problemas financeiros, pessoais, familiares, no casamento, também tem estado presentes dentre as razões do problema em estudo.

Prestes; Fialho; (2018) encontraram como resultados de sua pesquisa uma alta taxa de perdas financeiras causadas pelas evasões na Universidade Federal da Paraíba (UFPB), na qual demonstra as graves consequências econômicas e sociais que essa problemática vem causando as instituições de ensino e sociedade. Fialho (2018), infere sobre a necessidade de recursos financeiros para que se possam criar ações em combate ao abandono escolar, pois sem essa demanda a instituição se encontrará impedida de progredir em oferecer um melhor ensino, como também prejudicará milhares de pessoas e a pesquisa e extensão das universidades.

\subsection{Instituição de ensino Superior Privada}

Quanto ao âmbito de instituição privada, também pôde-se identificar causas da evasão ligadas à própria instituição de ensino, como levantado pelos autores Leonarde; Silvestre (2019), Lobo et al., (2019), Silva et al., (2018) que identificaram motivos como a estrutura da grade curricular dos cursos, sistema de avaliação, a dificuldade de interação entre os discentes e docentes, metodologias e o próprio processo de ensino e aprendizagem.

O estudo realizado por Boghi (2018) demonstrou a importância de uma abordagem mais interativa dos docentes com os discentes, trabalhando melhor a comunicação entre eles. $\mathrm{O}$ artigo infere como uma metodologia dinâmica e com uma participação mais ativa dos discentes com a disciplina, podendo promover a diminuição da taxa de evasão escolar no instituto de educação em análise.

Leonarde; Silvestre (2019) afirmam sobre a necessidade de as instituições, juntamente com os docentes, observarem novas formas de metodologias e avalições para que possam se adaptar melhor e conseguirem finalizar os cursos ingressados. Fávero et al., (2016) destacam causas como problemas pessoais e a falta de tempo para conciliar trabalho e estudos, já Oliveira; Moreira (2016) citam a não identificação com o curso e as dificuldades financeiras encontras pelos discentes.

O autor Souza et al., (2019) ainda afirma que a trajetória acadêmica se dá muito pela pressão social, na qual os estudantes não escolhem os cursos por vocação, mas sim por influências externas ou razões pessoais, como também 
profissionais. Sendo assim, a falta de identificação com o curso e a carreira profissional tem se destacado dentre as causas da evasão nas pesquisas dos autores Guimarães et al., (2019), Daitx; Loguercio (2016), Nascimento; Beggiato (2020), Rocha et al., (2020), Barbosa et al., (2016). Santos e Santos destaca também a elevada taxa de retenção em algumas disciplinas dos cursos iniciais como fator preponderante para o aumento na evasão nos cursos superiores (Santos \& Santos, 2019).

\subsection{Questões Específicas}

Alguns pesquisadores buscaram resultados que abordam questões mais específicas em seus trabalhos como Rangel et al., (2019), que inferem sobre a necessidade da problematização do emprego do conceito de evasão para referir-se a essa saída prematura, na qual em sua pesquisa pode-se perceber a necessidade contínua da precisão de tal conceito, pois os seus resultados diferem da literatura e na grande maioria das ações tomadas pelas instituições de ensino. Segundo ele, a evasão dos discentes em sua maioria não se configura apenas com o ato do abandono com o compromisso dos estudos, mas que os alunos alteram suas opções de estudos previamente de acordo com suas necessidades e condições de precariedade e jornadas de trabalho.

Partindo do mesmo princípio, Vitelli (2016) e Lima (2018) reforçam a importância da conceituação do termo evasão, tanto para criar um consenso sobre o conceito da própria evasão, quanto para que seja possível a realização de pesquisas e debates entre diferentes instituições de ensino, cursos e em demais âmbitos. Lima (2018) também certifica que a instituição de ensino do seu estudo classifica a evasão de 5 formas, sendo elas trancamento, cancelamento, abandono e as transferências internas e externas.

Bezerra; Moreira; (2018) concluem que a visualização de dados possibilita a utilização de meios digitais para o auxílio da produção de conhecimento, na qual pôde-se perceber que a utilização de imagens permitiu uma maior percepção pelos usuários. Quanto a evasão foi possível analisar e comparar aspectos de forma mais eficaz e consequentemente a identificação mais coerente das causas da evasão. Os resultados dão indícios de que a utilização das técnicas de métricas e de visualização facilitam a análise de evasão e da identificação de suas causas, possibilitando assim, a criação de ações para a redução do problema. Bizarria et al., (2017) apontaram a ligação entre o enfrentamento da evasão com o aumento da credibilidade que se possui uma instituição de ensino com funcionamento EAD. O mesmo autor aponta que as ações interpessoais devem ser geridas por estratégias da instituição com o intuito de constituir um maior vínculo.

O autor Branco (2020) demonstrou como o cálculo realizado da taxa de abandono e de conclusão contribuiu para um melhor entendimento das causas que levam a evasão escolar superior, indicando uma necessidade de revisão na seleção dos alunos, como também no seu acompanhamento, método de avaliação e gestão da educação. Por fim, o Prestes (2018) demonstrou em sua pesquisa, que a taxa anual de abandono é de 15\%, mas que vem apresentando um crescimento elevado na Universidade Federal da Paraíba (UFPB). Os efeitos sociais, individuais e educacionais da evasão estão ligados e atingem diretamente a instituição com prejuízos no orçamento e em sua forma de oferta da educação.

\subsection{Análise}

A análise dos resultados presentes nos artigos analisados leva a duas categorias: (i) as causas da evasão; (ii) formas de conceituar e analisar esse fenômeno. Com relação às causas da evasão, os estudos indicam principalmente questões ligadas ao aluno, como a falta de tempo para dedicação aos estudos, devido à carga horária de trabalho, a falta de identificação com o curso e a carreira profissional, e o surgimento de impedimentos de natureza financeira e familiar.

A evasão pode ter causas ligadas também à instituição de ensino, e na análise foram identificadas causas como o alto índice de reprovação ocasionando desestímulo para continuar, que por sua vez podem estar relacionadas com dificuldade de 
adequação com a grade curricular do curso, a metodologia de ensino adotada e a forma de avaliação. A baixa credibilidade da instituição de ensino também seria uma causa da evasão, pois prejudicaria o sentimento de vínculo entre aluno e instituição.

Com relação às formas de conceituar e analisar o fenômeno, observou-se que autores defendem a utilização de métricas validadas na elaboração de ações de ajuste nos processos de ensino e avaliação. Essas ações teriam objetivos como aumentar a participação do aluno no processo de ensino-aprendizagem (para que ele se torne o protagonista do processo) e possibilitar a realização de avaliações alinhadas com o método de ensino adotado.

\section{Considerações Finais}

Como foi demonstrado nos resultados, os motivos da evasão escolar se dão por multifatores e são vistos como fenômenos educacionais complexos, necessitando de diversas pesquisas para que se possa criar medidas preventivas com maior eficiência para amenizar o problema.

Diversas soluções são apresentadas pelos autores dos artigos analisados no presente estudo. Dentre elas é citada a necessidade da criação de novas políticas públicas que contemplem e analisem as diferentes necessidades das instituições educacionais. Pode-se identificar, conforme Leonarde; Silvestre (2019) e outros autores citaram, a necessidade de as instituições observarem e adaptarem as metodologias e formas de gestão para que se possa ter uma maior interatividade durante o curso entre os docentes e discentes, como também uma abordagem pedagógica de mais fácil entendimento, levando em conta que grande parte dos alunos necessitam conciliar uma jornada de trabalho com as atividades dos cursos. Daitx; Loguercio. (2016) infere até mesmo a necessidade de reformas curriculares visando e adaptando aos discentes da instituição de ensino, visando uma maior flexibilização do currículo oferta de horários alternativos para determinadas disciplinas.

Na presente revisão é possível identificar a importância da divulgação sobre os cursos, quanto ao que ele se propõe e os mercados de trabalho que eles possibilitam para os profissionais da área, para que os alunos possam ingressar com mais certeza sobre os cursos escolhidos e evitar a migração de cursos por desconhecimento, o que gera ociosidade de vagas em estágios mais avançados nos cursos. Nascimento; Beggiato; (2020) afirmam que minimizar a taxa de evasão dentro das instituições pode ampliar o número de profissionais em determinadas áreas, na qual possuem escassez de mão de obra, como é o caso da sua pesquisa que trabalhou com o curso de musicoterapia.

Portanto, infere-se que para tentar reduzir a evasão e garantir a permanência dos alunos é essencial o envolvimento das gestões de instituições de ensino, comprometimento dos alunos e de criação de políticas públicas pelo governo, uma vez que, com as multifaces desse problema, exigem múltiplas tomadas de ações com abordagens em diferentes âmbitos.

Para estudos futuros sugere-se ampliar o banco de dados da pesquisa incluindo publicações internacionais e incluir no escopo na pesquisa a evasão escolar do ensino técnico das instituições de ensino público e privado.

\section{Referências}

Baggi, C. A. S. \& Lopes D. A. (2011) Evasão e Avaliação Institucional no Ensino Superior: Uma discussão Bibliográfica. Revista da Avaliação da Educação Superior, Sorocaba, (16) 2.

Bizarria, F. P. A., Tassigny, M. M., \& Silva, Maria A. S. (2017). Formulações estratégicas para o enfrentamento da evasão escolar: o caso de uma Instituição de Ensino Superior no Ceará. Revista de Educação, Ciência e Cultura, (22)1.

Boghi, C., Shitsuka, R, Shitsuka, D. M., \& Conceição, M. M., (2018) Pesquisa-Ação no Desenvolvimento de Forma de Trabalho em Curso Superior a Distância. Revista Intersaberes, (14)29, 304-315. https://doi.org/10.22169/revint.v13i29.1395.

Branco, U. V. C. (2019). Ensino Superior Público e Privado na Paraíba nos Últimos 15 Anos: reflexões sobre o acesso, a permanência e a conclusão. Avaliação: Revista da Avaliação da Educação Superior, (25)44. https://doi.org/10.1590/s1414-40772020000100004.

Brasil Escola. (2021). Fracasso e evasão escolar. https://educador.brasilescola.uol.com.br/orientacao-escolar/fracasso-evasao-escolar.htm.

Brasil. (2010). Conferência Nacional de Educação. Conae-Final - CONAE 2010.62. http://conae.mec.gov.br/images/stories/doc/doc_ref_conae.rtf. 
Brasil. (2014). Lei n.13.005, de 25 de junho de 2014. Aprova o Plano Nacional de Educação - PNE e dá outras providências. Diário Oficial da União, Brasília, DF. http://pne.mec.gov.br/18-planos-subnacionais-de-educacao/543-plano-nacional-de-educacao-lei-n-13-005-2014.

Brasil. (2015). Ministério da Educação. Documento Orientador para a Superação da Evasão e Retenção na Rede Federal de Educação Profissional, Científica e Tecnológica. p. 15. https://portal.ifpe.edu.br/campus/paulista/assistencia-estudantil/documento-orientador-setec_evasao-e-retencao-na-rede-federal.pdf.

Brum, D. V., Gamenha, D. E. S., \& Pereira, M. B. S. (2018). Panorama da Evasão e Permanência no Ensino Superior no Instituto Federal de Rondônia - Porto Velho Zona Norte. Brazilian Applied Science Review, (2)1, 357-369. Curitiba.

Daitx, A. C., Loguercio, R. Q., \& Strack, R. (2016). Evasão e Retenção Escolar no Curso de Licenciatura em Química do Instituto de Química da UFRGS. Investigações em Ensino de Ciências, (21)2, 153-179.

Denzin, N. K., \& Lincoln, Y. S. (2006) O planejamento da pesquisa qualitativa: teorias e abordagens. (2a ed.), Artmed.

Fávero, J. D., Parisotto, I. R. S., \& Carvalho, L. C. (2016). Análise Discriminante das Formas de Evasão de uma Instituição de Ensino Superior. Revista da UNIFEBE, (1)19.

Fritsch, R., Rocha, C. S., \& Vitelli, R. F., (2015). A evasão nos cursos de graduação em uma instituição de ensino superior privada. Revista Educação em Questão, (52)38, 81-108. 10.21680/1981-1802.2015v52n38ID7963

Gil, A. C. (2008). Métodos e Técnicas de Pesquisa Social. (6a ed.), Atlas.

Guimarães, O. M., Lima, M. J. O., \& Martins, E. C. B. (2019). A Evasão no Ensino Superior: A UNESP Campus de Franca - PERIODO DE $2013-2018$. Revista Camine: Caminhos da Educação, (11)2. Franca.

Lamers, J. M. S., Santos, B. S., \& Toass, R. F. C. (2017). Retenção e Evasão no Ensino Superior Público: Estudo de Caso em um Curso Noturno de Odontologia. Educação em Revista, 33. http://dx.doi.org/10.1590/0102-4698154730.

Leonarde, G. S. S., \& Silvestre, Luiz H. A. S. (2020). Caracterização da Evasão no Curso de Administração da Universidade Federal dos Vales do Jequitinhonha e Mucuri - Campus do Mucuri, entre 2014 e 2018. Research, Society and Development, (9)2. https://doi.org/10.33448/rsd-v9i2.1953

Lima, F. S., \& Zago, Nadir. (2018). Desafios Conceituais e Tendências da Evasão no Ensino Superior: a realidade de uma universidade comunitária. Revista Internacional de Educação Superior, (4)2, 366-386, SP.

Lobo, J.S, Ribeiro, J.B P., \& Moreira J. R., (2019). Entendendo a Insatisfação Acadêmica como Fator de Evasão Escolar: Percepção dos Estudantes Evadidos do Curso de Administração (2017 - 2018) do Centro Universitário Projeção. Revista Projeção e Docência, (10)1.

Nascimento, L. C. S., Beggiato, \& S. M. O., (2020). Evasão escolar na graduação em Musicoterapia da Universidade Estadual do Paraná. Educação \& Formação, (5)3, 2080.

Oliveira, G. C. A., \& Moreira, J. R. (2016). A Voz da evasão: Análise da evasão escolar em uma instituição de educação superior privada. projeção $e$ docência, (7)2.

Pereira, A. S., Sthitsuka, D. M., Pereira, F. J., \& Shitsuka, R. (2018) Metodologia da Pesquisa Científica, Universidade Federal de Santa Maria. Núcleo de Tecnologia Educacional, https://repositorio.ufsm.br/bitstream/handle/1/15824/Lic_Computacao_Metodologia-Pesquisa-Cientifica.pdf?sequence=1.

Preste, E. M. T., \& Fialho, M. G. D. (2018). Evasão na educação superior e gestão institucional: o caso da Universidade Federal da Paraíba. Ensaio: Avaliação e Políticas Públicas em Educação, (26)100, 869-889.

Rangel, F. O. et al. (2019). Evasão ou mobilidade: conceito e realidade em uma licenciatura. Ciência \& Educação, 1, 25-42. https://doi.org/10.1590/1516731320190010003 .

Rocha, J. S., Nascimento, R., R., Lima, T. S., Pittarelli, B., F. S., Silva, G. A. R., Rosa, M.L. \& Magalhães, A. P. (2020). Evasão escolar no curso de licenciatura em química no IFPR Campus Paranavaí: um levantamento das possíveis causas. Brazilian Journal of Development, (6) 4,20778-20797. Curitiba. DOI:10.34117/bjdv6n4-305.

Rodrigues, L. S., Gontijo, T., L., Cavalcante, R. B., Oliveira, P., P. \& Duarte, S. J. H. (2018). A Evasão em um Curso de Especialização em Gestão em Saúde na Modalidade a Distância. Interface, (22)66, Botucatu. http://dx.doi.org/10.1590/1807-57622017.0129

Santos, C. M., \& Santos, A..T.O., (2019) A implantação do Programação REUNI na UFVJM sob a ótica dos Bacharelados Interdisciplinares e Engenharias, Res. Research, Society and Development, (8)11.

Silva, R. C., Moraes, A.F. M., \& Costa, G. V. (2018). Fatores que Podem Interferir na Evasão Escolar em uma Instituição de Ensino Superior Privada. Revista CESUMAR, (23)2, 205-228.

Souza, T. Santos, Sá, S., \& Castro, P. A. (2019). Evasão Escolar no Ensino Superior: um estudo qualitativo via mapeamento de licenciaturas. Revista Lusófona de Educação, (44) 44 .

Unesp, Universidade Estadual Paulista. (2020). Tipos de Revisão de Literatura. Botucatu. Vitelli, R. F., Fritsch, R. (2016). Evasão Escolar na e Educação Superior: de que indicador estamos falando? Estudos em Avaliação Educacional, (27)66, 908-937.

Wilhelml, M. F., \& Schlosserll, M. T. S. (2019). Evasão no curso de licenciatura em geografia da Universidade Estadual do Oeste do Paraná (UNIOESTE): indagações e complexidades. Geografia Ensino \& Pesquisa, (23). 